\title{
Critical Care Management of Decompensated Right Heart Failure in Pulmonary Arterial Hypertension Patients - An Ongoing Approach
}

\author{
Ioan Tilea1,2, Andreea Varga ${ }^{1 *}$, Anca-Meda Georgescu1,3, Bianca-Liana Grigorescu ${ }^{1,4}$ \\ 1 George Emil Palade University of Medicine, Pharmacy, Science, and Technology of Targu Mures, Romania \\ 2 Department of Cardiology II, Emergency Clinical County Hospital, Targu Mures, Romania \\ 3 Infectious Disease Clinic, Clinical County Hospital, Targu Mures, Romania \\ ${ }^{4}$ Department of Anaesthesia and Intensive Care, Emergency Clinical County Hospital, Targu Mures, Romania
}

\begin{abstract}
Despite substantial advancements in diagnosis and specific medical therapy in pulmonary arterial hypertension patients' management, this condition continues to represent a major cause of mortality worldwide. In pulmonary arterial hypertension, the continuous increase of pulmonary vascular resistance and rapid development of right heart failure determine a poor prognosis. Against targeted therapy, patients inexorable deteriorate over time. Pulmonary arterial hypertension patients with acute right heart failure who need intensive care unit admission present a complexity of the disease pathophysiology. Intensive care management challenges are multifaceted. Awareness of algorithms of right-sided heart failure monitoring in intensive care units, targeted pulmonary hypertension therapies, and recognition of precipitating factors, hemodynamic instability and progressive multisystem organ failure requires a multidisciplinary pulmonary hypertension team. This paper summarizes the management strategies of acute rightsided heart failure in pulmonary arterial hypertension adult cases based on recently available data.
\end{abstract}

Keywords: pulmonary arterial hypertension, acute right heart failure, hemodynamic, specific therapy, intensive care admission, management

Received: 30 May 2021 / Accepted: 21 June 2021

\section{INTRODUCTION}

Pulmonary hypertension $(\mathrm{PH})$ is a cardiopulmonary condition with progressive discouraging evolution, defined by a resting value $\geq 25 \mathrm{mmHg}$ of mean pulmonary arterial pressure (mPAP) measured by right heart catheterization (RHC) [1]. The value of $15 \mathrm{mmHg}$ of the pulmonary artery wedge pressure (PAWP) along with $\mathrm{MPAP}$ discern two major forms of $\mathrm{PH}$ : precapillary (mPAP $\geq 25 \mathrm{mmHg}$, and PAWP $\leq 15 \mathrm{mmHg}$ ), and postcapillary $\mathrm{PH}$ (mPAP $\geq 25 \mathrm{mmHg}$, and PAWP $>15$ $\mathrm{mmHg}$ ), respectively. A new definition proposed at The Sixth World Symposium in Pulmonary Hypertension consider a mPAP $>20 \mathrm{mmHg}$, and precapillary $\mathrm{PH}$ is defined as $\mathrm{mPAP}>20 \mathrm{mmHg}$, $\mathrm{PAWP} \leq 15 \mathrm{mmHg}$ and pulmonary vascular resistance (PVR) $\geq 3 \mathrm{WU}$ [2].

Related to etiology, clinical presentation, hemodynamic data and pathological findings, $\mathrm{PH}$ is clinically classified into five groups and the therapeutic approach is patient-centred with common general measures and supportive therapies [1].
As a distinctive disease with multiple aetiologies, pulmonary arterial hypertension (PAH) is recognized as a cause of acute and chronic right-sided heart failure (RHF), but the clinical onset of the RHF is variable among different subgroups of PAH with similar degree of pulmonary pressure $[3,4]$. Data regarding admission, management, and outcomes of $\mathrm{PAH}$ patients in intensive care unit (ICU) are still limited, as a result of small number of diagnosed cases and lack of consisting data [5-7].

Intensive care unit admissions of acute decompensated right heart failure PAH patients present a complexity of disease pathophysiology and frequently a desolating short-term prognosis. The in-hospital mortality percentage is ranging from $26 \%$ up to $41 \%$ or higher in patients who require high doses of vasopressors and/or inotropes (50\%) up to 70\% in dialyzed cases [8-13].

Intensive care management challenges are multifaceted: trigger factors identification and treatment (case specific), volume optimization, right ventricular func- 
tion support, preserve cardiac output for adequate systemic perfusion, and pharmacological aspects (kinetics, molecular, biochemical, and effects) of PAH specific drugs [14-16]. Recognition of underlying cause, hemodynamic instability and progressive multisystem organ failure requires a multidisciplinary $\mathrm{PH}$ team.

This overview summarizes the management strategies of acute right-sided heart failure in pulmonary arterial hypertension adult cases based on recent available data.

\section{PULMONARY ARTERIAL HYPERTENSION - A StATE Of KNOWLedge}

Pulmonary arterial hypertension classified as group 1 in ESC/ERS guidelines, encompasses distinctive subgroups: 1.1-idiopathic, 1.2-heritable (1.2.1-bone morphogenetic protein receptor type 2 (BMPR2) gene mutation, 1.2.2-other gene mutations (notable level of evidence for EIF2AK4, TBX4, ATP13A3, GDF2, SOX17, AQP1, ACVRL1, SMAD9, ENG, KCNK3, CAV1), 1.3-drugs and toxins induced, and 1.4-associated with 1.4.1-connective tissue disease, 1.4.2-human immunodeficiency virus infection, 1.4.3-portal hypertension, 1.4.4-congenital heart disease and 1.4.5-schistosomiasis [1, 17-19].

Real-life data related to $\mathrm{PAH}$ are derived from local, national and/or multinational registries, and observational studies [20,21]. The continuous increase of PVR and rapid development of RHF determines a poor prognosis, despite pulmonary vasodilator therapies development based on disease pathophysiology [22]. McLaughlin et al. exposed the survival rates of PAH patients at 1-, 3-, and 5-year follow-up; noticeable, the rates vary considerable in different subgroups of $\mathrm{PAH}$, being especially related to the underlying etiology [23]. However, the outcomes analysis of an US cohort (REVEAL Registry) and a French study, advise a 69\% and $83 \%$ respectively survival rate at 3-year follow-up in $\mathrm{PAH}$ patients on specific regimens combination [24, 25].

The incidence, prevalence, and phenotype of PAH display differences between studies, registries, presumably related to the design, structure biases, ranging from 2 to 52 cases per million inhabitants [1,26-30].

A remarkable registries derived result is related to the development of prognostic equations for survival probability and risk calculators. Currently available prognostic equations include hemodynamic data obtained at the moment of $\mathrm{PH}$ diagnosis - mPAP, mean right atrial pressure (mRAP), cardiac index (CI), and mixed venous oxygen saturation $\left(\mathrm{SvO}_{2}\right)$ which can be used as right ventricle function indicators as well as further guided management of PAH patients [31-33].

Main hemodynamic and oxygenation data normal values that are currently used in diagnosis, regular follow-up or ICU monitoring are depicted in table 1.

Different risk calculators used in present-day, built on multiple parameters (demographics, comorbidities, clinical, hemodynamic, functional, echocardiography, lab tests) are designed to offer practitioners valuable tools for an individualized treatment to obtain a lowrisk profile of PAH patients [1,36-38].

Endothelial dysfunction and vascular fibrosis play a key-role in the development and disease advancement. Studies on angiogenesis, endothelial-mesenchymal transition, epigenetics, and voltage-gated ion channels biology are on-going [39].

Disease-specific and easily accessible biomarkers of PAH or aberrant pulmonary vascular remodellingrelated are currently unavailable, mainly considering the heterogeneity of the PAH population $[1,40,41]$. Nterminal pro-brain natriuretic peptide (NT-proBNP), currently associated with disease severity and survival, is a non-specific PAH biomarker. Used in heart failure (HF) diagnosis and as predictor of mortality for decompensated HF, its levels can be influenced by multiple comorbidities [42-45]. At present, biomarkers associated with endothelin-1 pathway (ET-1), nitric oxide pathway (cGMP, ADMA, SDMA, nitrate, nitrite, S-nitrosothiol), galectin 3, soluble suppression of tumorigenicity (ST-2), troponins, osteopontin are studied, but the results must be validated by further research $[1,11,46-48]$. Promising data were published by Samokhin et al related to the NEDD9 plasma level role on pulmonary arterial remodelling, abnormal hemodynamic, and clinical events in PAH patients [49].

The complex and multifactorial pathophysiology of $\mathrm{PAH}$, the presence of three different pathways contributed to the development of approved specific treatment options since 1995. Acute vasoreactivity testing using a short-acting pulmonary vasodilator (intravenous epoprostenol or adenosine, inhaled nitric oxide, inhaled iloprost) should be performed after PAH diagnosis confirmation. A decrease in mean $\mathrm{PAP} \geq 10 \mathrm{mmHg}$ to reach a value $<40 \mathrm{mmHg}$ with an unchanged or increased cardiac index confirm channel blocker (CCB) responders. In patients with $\mathrm{CI}<2 \mathrm{~L} / \mathrm{min} / \mathrm{m}^{2}$ or RAP $>15 \mathrm{mmHg}$ treatment with CCB should be considered useless [3]. 
Table 1. The main hemodynamic and oxygenation parameters considered in diagnosis and monitoring PAH patients (adapted from [34, 35])

\section{Hemodynamic parameters}

Systolic blood pressure (SBP)

Diastolic blood pressure (DBP)

Mean arterial pressure (MAP)

Heart rate (HR)

Right atrial pressure (RAP)

Right ventricular systolic pressure (RVSP)

Right ventricular diastolic pressure (RVDP)

Pulmonary artery systolic pressure (PASP)

Pulmonary artery diastolic pressure (PADP)

Mean pulmonary artery pressure

(mPAP)

Pulmonary capillary wedge pressure (PCWP)

Cardiac output (CO)

Cardiac index $(\mathrm{Cl})$

Stroke volume (SV)

Stroke volume index (SVI)

Systemic vascular resistance

(SVR)

Systemic vascular resistance

index (SVRI)

Pulmonary vascular resistance (PVR)

Pulmonary vascular resistance index (PVRI)

Partial pressure of arterial oxygen $\left(\mathrm{PaO}_{2}\right)$

Partial pressure of arterial $\mathrm{CO}_{2}$

$\left(\mathrm{PaCO}_{2}\right)$

Bicarbonate $\left(\mathrm{HCO}_{3}\right)$

$\mathrm{pH}$

Arterial oxygen saturation $\left(\mathrm{SaO}_{2}\right)$

Mixed venous saturation $\left(\mathrm{SvO}_{2}\right)$

Oxygen delivery $\left(\mathrm{DO}_{2}\right)$

Oxygen delivery index $\left(\mathrm{DO}_{2} \mathrm{l}\right)$

Oxygen consumption $\left(\mathrm{VO}_{2}\right)$

Oxygen consumption index $\left(\mathrm{VO}_{2} \mathrm{I}\right)$

Oxygen extraction ratio $\left(\mathrm{O}_{2} \mathrm{ER}\right)$

Oxygen extraction Index $\left(\mathrm{O}_{2} \mathrm{EI}\right)$

\section{Normal range}

90-140 mmHg

60-90 mmHg

$[\mathrm{SBP}+(2 \times \mathrm{DBP})] / 3$

70-100 mmHg

60-100 bpm

$\leq 6 \mathrm{mmHg}$

15-30 mmHg

$1-8 \mathrm{mmHg}$

$15-30 \mathrm{mmHg}$

6-12 $\mathrm{mmHg}$

9-18 $\mathrm{mmHg}$

$\leq 12 \mathrm{mmHg}$

$\mathrm{HR} \times \mathrm{SV} / 1000$

CO/BSA

$\mathrm{CO} / \mathrm{HR} \times 1000$

4-8 L/min

2.6-4.2 L/min/m²

$60-120 \mathrm{~mL} /$ beat

$\mathrm{Cl} / \mathrm{HR} \times 1000$

(MAP-mean RA/CO) $\times 80$

40-50 mL/beat $/ \mathrm{m}^{2}$

800-1200 dynes x s/cm5

10-15 WU

1970-2390 dynes x s/cm5 $/ \mathrm{m}^{2}$

24.6-29.8 WU

(mPAP-mean PCWP/CO) $\times 80$

$120-250$ dynes $\times \mathrm{s} / \mathrm{cm}^{5}$

1.5-3.1 WU

255-285 dynes x s/cm5 $/ \mathrm{m}^{2}$

$80 \times($ MPAP- PAWP)/Cl

3.2-3.6 WU

80-100 $\mathrm{mmHg}$

$35-45 \mathrm{mmHg}$

$22-28 \mathrm{mEq} / \mathrm{L}$

$7.38-7.42$

$95-100 \%$

$60-80 \%$

$950-1150 \mathrm{~mL} / \mathrm{min}$

$500-600 \mathrm{~mL} / \mathrm{min} / \mathrm{m}^{2}$

$200-250 \mathrm{~mL} / \mathrm{min}$

$120-160 \mathrm{~mL} / \mathrm{min} / \mathrm{m}^{2}$

$22-30 \%$

$20-25 \%$
Currently, there are 14 drugs approved for PAH specific treatment, delivered using 4 administration routes [50]. Approved drugs for use in $\mathrm{PAH}$ patients, usual dosage and administration route are depicted in table 2.

Specific medications used in PAH treatment primarily target the pulmonary vasculature, with minimal effects on right ventricle [53]. The lack of long-term improvement in PA pressures even by using modern specific PAH therapies (prostanoids) may be related to the progression of the disease [54].
Despite PAH-specific combination regimens, patients still deteriorate over time and other treatment options (balloon atrial septostomy, surgical or transcatheter Potts shunt, pulmonary artery denervation) should be considered before lung or heart-lung transplantation [55].

In order to avoid late diagnosis with displayed RHF symptoms and signs, disease increased awareness, early referrals to $\mathrm{PH}$ reference centers and a well-precise initial treatment is required. 
With disease advance, PAH patients need frequent hospitalizations for repeated decompensations and admission in intensive care units in acute episodes of right ventricular failure (RVF).

\section{The Right VentricLe -The ForgotTen Chamber Of THE HeART}

Advocate by the Cologne Consensus Conference 2018 and 6th World Symposium on Pulmonary Hypertension, although there is no standard definition, the right-sided heart failure is characterised by the two statements:

- systolic and/or diastolic right ventricular dysfunction drives to low cardiac output and/or elevated right-sided filling pressures (increased right ventricular afterload)

- right-sided HF is severe if it leads to secondary dysfunction of other organs and tissues, in particular liver, kidneys, and gut $[4,5,56,57]$.

Fundamental definitions of the components of the right heart system, distinction between RHF and RVF and what represents RHF were proposed by the International Right Heart Foundation Working Group [58]. Mehra et al recommend RHF as "a clinical syndrome due to an alteration of structure and/or function of the right heart circulatory system that leads to sub-optimal delivery of blood flow (high or low) to the pulmonary circulation and/or elevated venous pressures at rest or with exercise" [58].

\section{Pathophysiology}

By clinical perspective, RHF is a complex syndrome with signs and symptoms' resulting from impaired RV structure or function and both appears to be common in severely ill patients [3].

Systolic RHF and diastolic RHF may present as isolated systolic or isolated diastolic RHF, however combined forms frequently require patient's admission and treatment to the ICU. Tissue perfusion and oxygenation detriment is consequential to left ventricular underfilling and low cardiac output in systolic RHF. In diastolic RHF altered tissue perfusion and oxygenation as well, is the consequence of elevated systemic venous pressure [59]. Detailed pathophysiology mechanisms of right ventricular failure, ventricular interdependence, shifting of interventricular septum, pericardial mechanical involvement in RVF are detailed discussed elsewhere [5,60,61] (figure 1).

\section{The Patient With PUlmonary ARterial HYPERTENSION AND ACUTE DECOMPEN- SATED RIGHT HEART FAILURE}

\section{Intensive care unit management}

Facing with a PAH patient with clinical signs of acute decompensated RHF failure including signs of low CO, congestion in the setting of RV failure reworking to pressure or volume overload, impaired venous return should be detected [62].

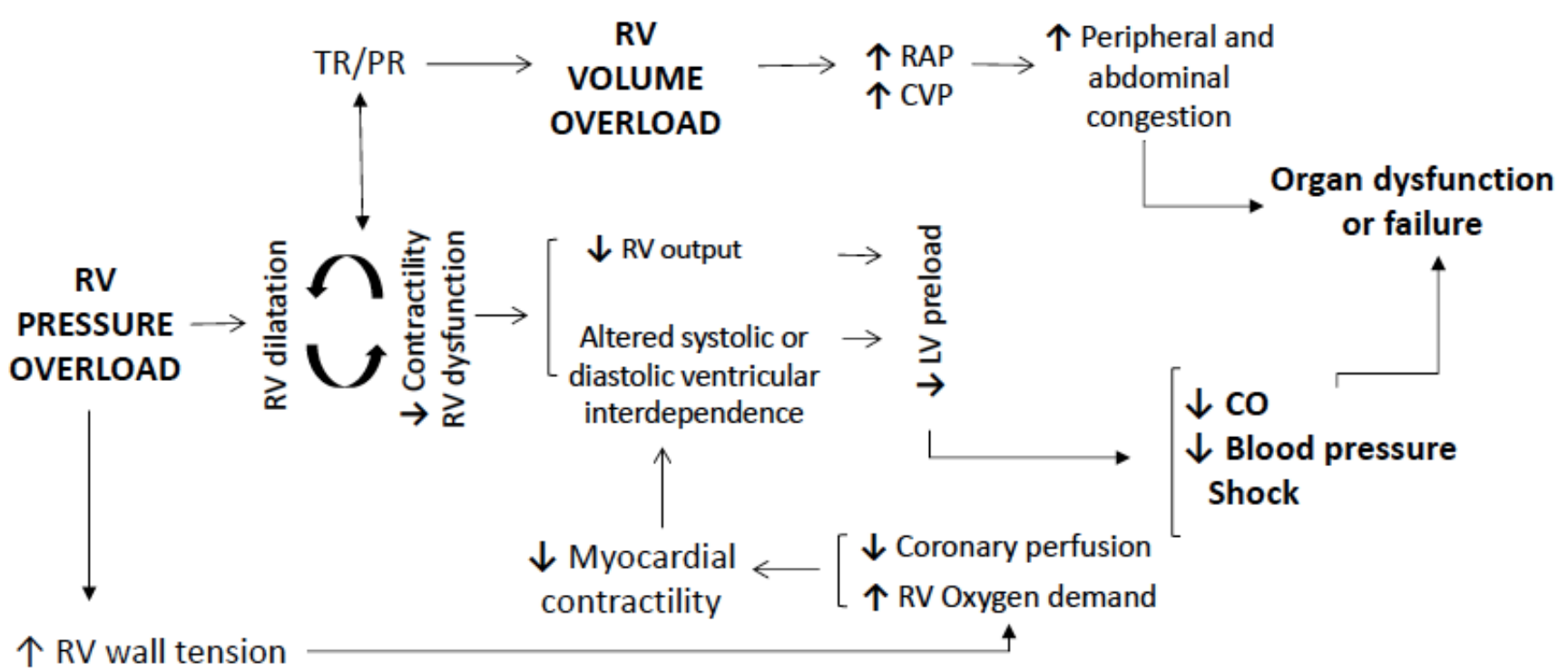

Fig. 1. Schematic pathophysiology of right ventricular failure. Abbreviations: CO-cardiac output, CVP-central venous pressure, LV-left ventricle, TR-tricuspid regurgitation, PR-pulmonary regurgitation, RAP-right atrial pressure, RV-right ventricle. 
174 - The Journal of Critical Care Medicine 2021;7(3)

Available online at: www.jccm.ro

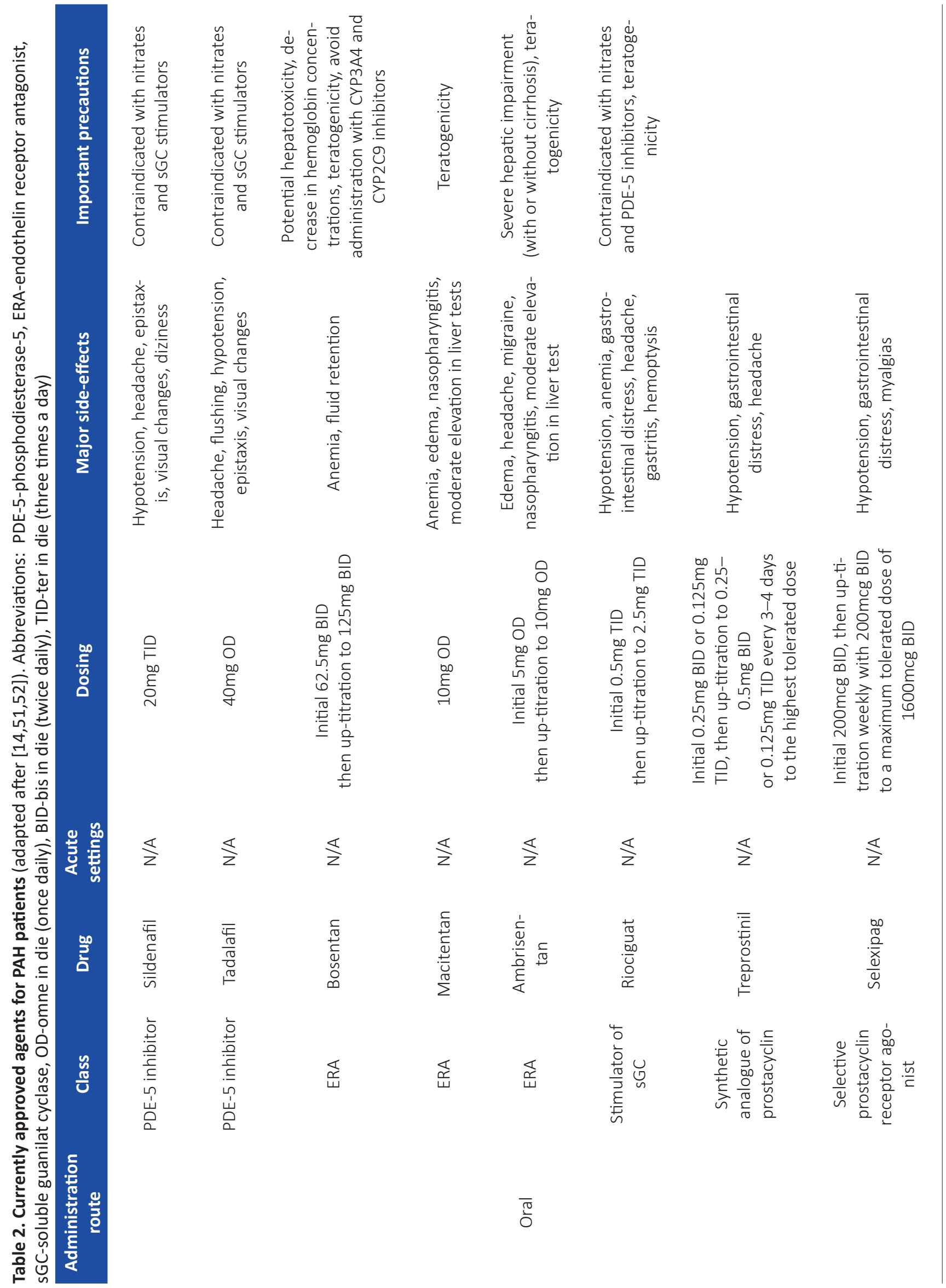




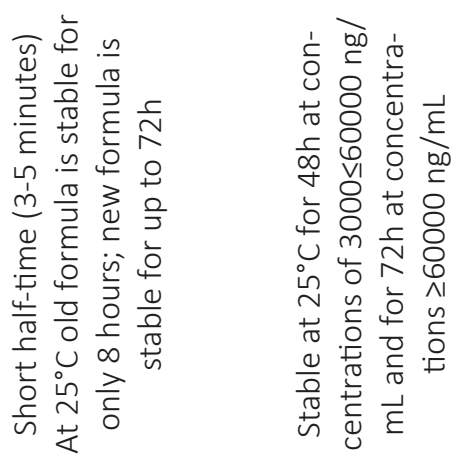

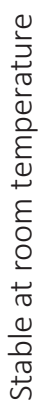

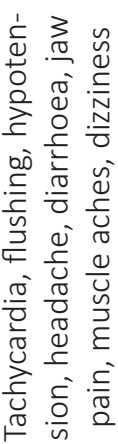
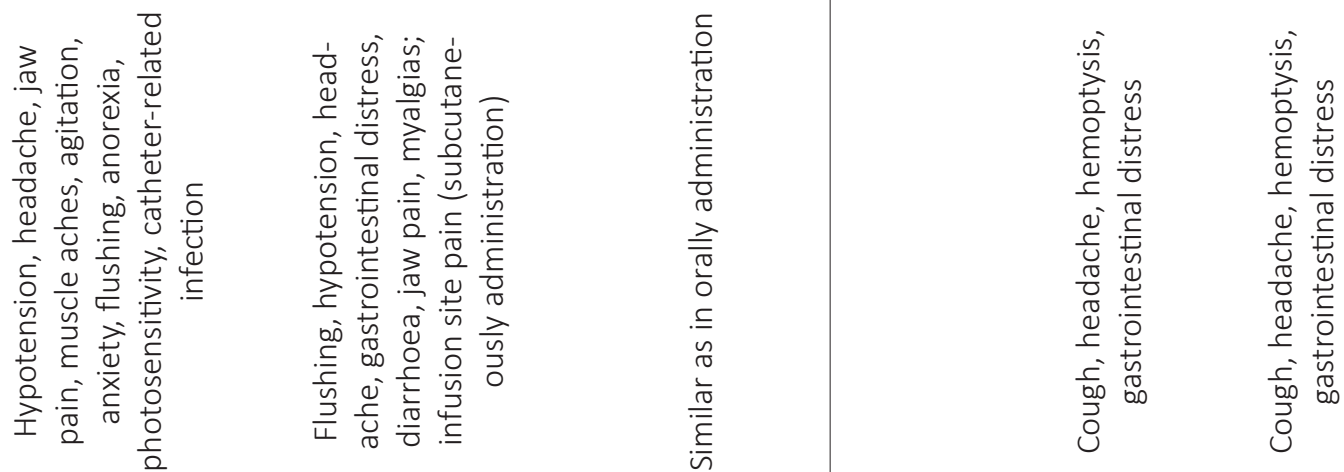

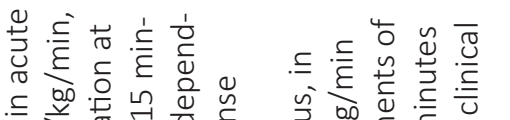

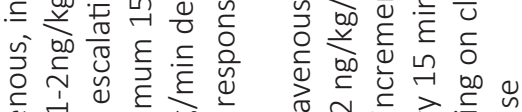

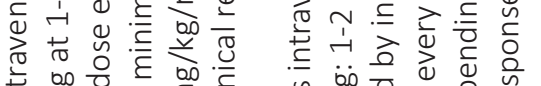

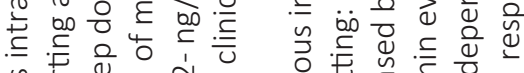

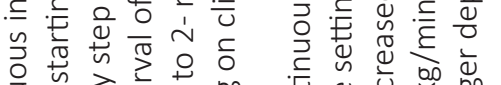

을

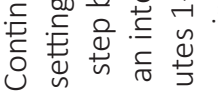

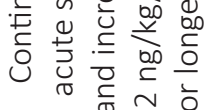

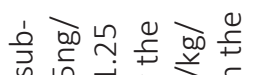

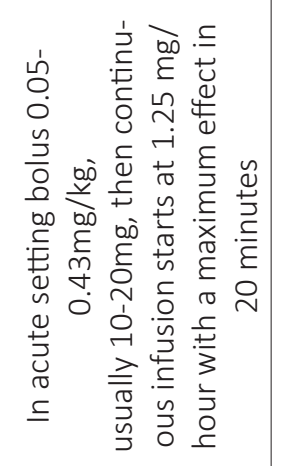

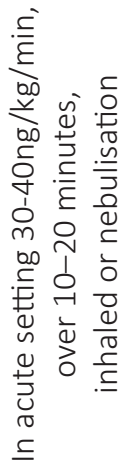

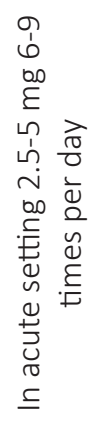

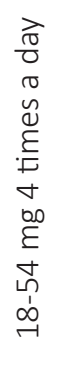

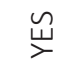

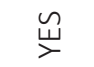

$\underset{z}{\Sigma}$

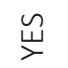

出

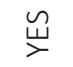

$\frac{\varangle}{z}$

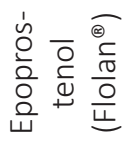

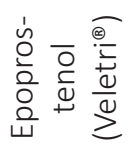

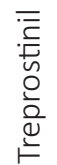

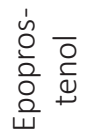

ก
$\stackrel{0}{0}$

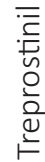

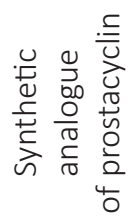
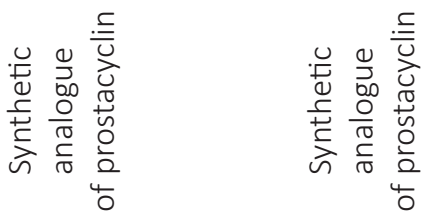

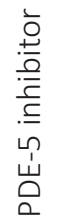

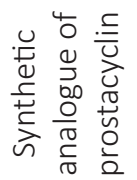

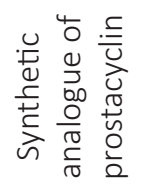

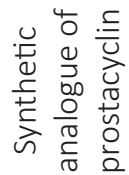

$\frac{\bar{\alpha}}{\frac{\pi}{4}}$

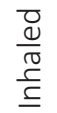


The greatest importance to the ICU monitoring of $\mathrm{PAH}$ and severe right-sided heart failure patients are clinical signs, cardiac and organ's functions [16] (figure 2).

\section{Basic ICU monitoring and laboratory tests}

Monitoring clinical signs is the first step in PAH patients admitted in ICU. WHO functional class improvement, maintaining sinus rhythm, reducing tachycardia, a negative fluid balance, decrease of jugular venous pressure, preserving a SBP over $90 \mathrm{mmHg}$ with a MAP $>70$ $\mathrm{mmHg}$, avoiding acute renal and hepatic injuries are mandatory. Urinary output measured by continuous catheterization must be $>0.5 \mathrm{~mL} / \mathrm{kg} /$ hour. Commonly lab tests are depicted in figure 2 . Serial checks of natriuretic peptides (BNP or/and NT-proBNP) levels should be completed.

\section{Echocardiography}

Against the RV difficult anatomy, cardiac function evaluation and valve assessment by echocardiographic parameters is an essential key examination in monitoring the continuity of RV evolution. The right ventricle worsening, determining the ventricular dyssynchrony by time to peak strain is a good parameter to evaluate the interdependence of left and right ventricle [63].

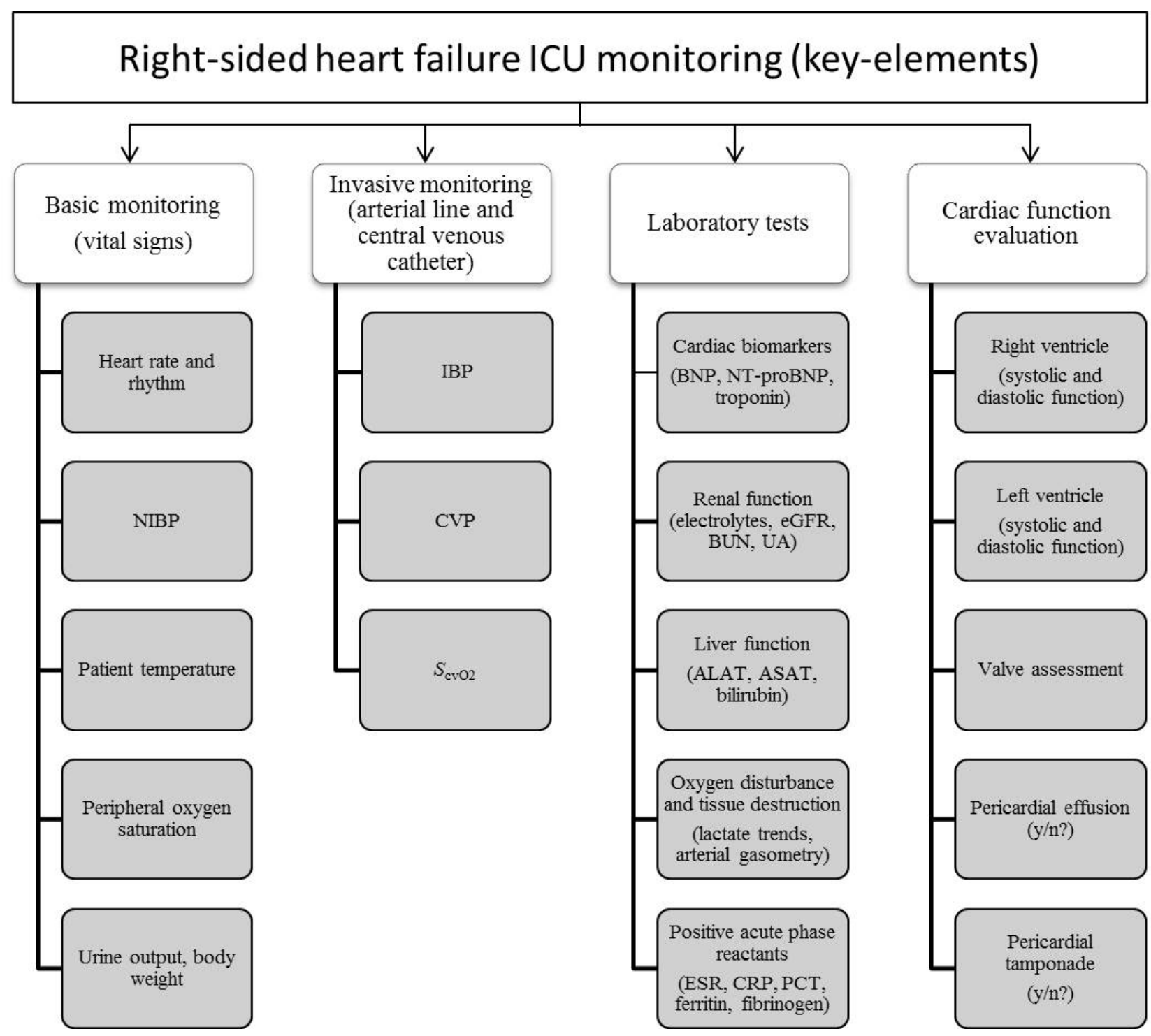

Fig. 2. Algorithm of right-sided heart failure monitoring in ICU. Abbreviations: ICU-intensive care unit, NIBP-non-invasive blood pressure, IBP-invasive blood pressure, CVP-central venous pressure, ScvO2-central venous oxygen saturation, BNP-brain natriuretic peptide, NT-proBNP-N-terminal pro-brain natriuretic peptide, eGFR-estimated glomerular filtration rate, BUN-blood urea nitrogen, UA-uric acid, ALAT-alanine transaminase, ASAT-aspartate transaminase, ESR-erythrocyte sedimentation rate, CRP-C-reactive protein, PCT-procalcitonin, LV-left ventricle, RV-right ventricle. 
In critically ill patients, serial quantitative RV function by tricuspid annular plane systolic excursion (TAPSE), S' velocity of the tricuspid annulus, RV index of myocardial performance (RIPM) and/or fractional area change (FAC) assessment are supported by contemporary management of acute RVF [59]. Other parameters, such as right atrium area, inferior vena cava diameter, $\mathrm{RV} / \mathrm{LV}$ ratio, and LV eccentricity index, pericardial effusion, and parameters of LV filling or advance use of the three-dimensional (3D) imaging studies, enhance the non-invasive evaluation of the RV dysfunction progression [64].

Management of PAH patients admitted in the ICU with acute RHF should target the reduction of pulmonary vascular resistance [52]. This could be achieved primary by identifying and prompt treatment of the triggering factors.

\section{Hemodynamic monitoring}

Invasive hemodynamic monitoring (arterial and central venous lines) is essential to guide therapy. The main goals are maintaining a normal blood pressure for each case, a CVP of 8-12 mm Hg and tailor drugs administration for a normal CO. Standard placement of a pulmonary artery catheter or a Swan-Ganz one to monitor PCWP, PVR, CO, and transpulmonary pressure gradient is attributable in complex patients [65]. An adequate titration of prostanoid therapy, inotropes, diuretics can be driven by the real-time data obtained, but these catheters are carrying-out the risk of arrhythmias [66]. Advanced hemodynamic monitoring can be performed using minimally/non-invasive systems such as pulse index continuous cardiac output device (PiC$\mathrm{CO}$ ), lithium dilution techniques (LiDCO) $[67,68]$. In special conditions (extended hemodynamic evaluation or severe PAH patients) right heart catheterization can be considered.

\section{Intensive care unit therapy aims}

\section{Management of treatable triggering factors}

Common treatable triggering factors who determine ICU admission of PAH patients are represented by infection, arrhythmias, anaemia, pulmonary embolism, systemic hypotension, or specific medication withdrawal/noncompliance [16].

\section{Infection}

Infections (including sepsis, infective endocarditis, cerebral abscesses, confirmed HIV) are important negative prognostic factors for mortality in $\mathrm{PAH}$ pa- tients admitted in the ICU. They are substantial evidence in favour of connections between gut pathology and PAH $[69,70]$. The presence of biofilms on indwelling medical devices is another important source of infection. When are diagnosed (isolation of microorganism or high clinical suspicion, radiologic findings, blood samples), prompted targeted treatment decision should be taken by a multidisciplinary team (including infection diseases advocacy). Removal the possibly infected line should be performed, but an alternative route (preferably a central line) must be commenced before (caution related to short half-time of prostacyclins).

\section{Arrhythmias}

With limited and various patients study population, the burden of arrhythmias in PAH mostly supraventricular (tachycardias, atrial fibrillation, atrial flutter, and atrioventricular nodal re-entry tachycardia), and ventricular arrythmias is less clear [71]. Supraventricular arrythmias (SVA), with a cumulative incidence ranging from $13.2 \%$ to $25.1 \%$, are linked to a marked clinical deterioration, and considered to be a negative prognostic marker of evolution to the endstage [72-75]. The onset of SVA is associated with right ventricle failure and death [76]. The maintenance or restoring sinus rhythm should be pursued; rhythm control is another option. Among medications used in the treatment of arrythmias, the first choice is Amiodarone; other drugs (Digoxin, Sotalol, Dronedaron, beta-blockers, CCBs) are less studied and they should be used in well-definite scenarios, carrying-out a highrisk in patients with severe RV dysfunction. Alternative procedures - direct electric cardioversion (DCCV) or electrophysiologic therapies (ablations, AAD's, overdrive pacing) must be also individualized and performed in specialized centers [77]. DCCV requires anaesthetic support, carries out a significant risk, and should be ordered before irreversible haemodynamic changes occur. There are no clear indications for prophylactic implantation of ICD in PAH patients [78]. Anticoagulation should be initiated in all patients accordingly to individual patterns. The CHA2DS2-VASc score is not validated in PAH.

Anaemia can precipitate acute RHF in PAH patients, encompasses different etiologies and, therefore, should be carefully corrected [79]. The real incidence of iron-deficiency anemia is not well-known in PAH subgroups, but represents a common comorbidity in HF. Iron replacement using intravenous ferric car- 
boxymaltose may be used in acute episodes of HF in PAH patients, reducing hospitalization but the effect on 1-year mortality is still in debate $[80,81]$.

Haemoptysis represent a potentially cause of acute anemia in acute RHF PAH patients. Depending on etiology (including previous anticoagulation), severity, and source of bleeding, it can negative impact the patients management. Severity of haemoptysis can be closely related to the underlying mechanisms: pulmonary embolism, and/or the sequence of elevated PAP, development of functional microvascular networks and association of changes in the structural and functional bronchial arteries.

Bleedings related to anticoagulants address their withholding, the use of traditional reversal agents including prothrombin concentrate in case of vitamin $\mathrm{K}$ antagonists or novel reversal agents for DOACs (Idarucizumab, Adexanet alfa) [82,83]. Particular cases of bleedings in PAH-Eisenmenger syndrome-related should be prudentially treated with tranexamic acid. In abundant haemoptysis, tranexamic acid represents an option for rapid resolution of bleeding in case of multiple bronchial artery embolization is unavailable $[84,85]$. Specific PAH cases with major haemoptysis should grant the use of desmopressin [86].

In PAH patients with acute RVF related to an of acute pulmonary embolism episode, treatment should be initiated accordingly to current guidelines, but the effect of thrombolysis can be unpredictable $[59,87]$.

\section{Ventilation issues}

Oxygen inhalations reduce PVR hypoxia-related, mPAP and improve cardiac output [88]. As is stated by Price et al, inadequate oxygenation can exacerbate pulmonary vasoconstriction via hypoxia, hypercapnia and acidosis [89]. Oxygen saturations $\left(\mathrm{SaO}_{2}\right)$ should be kept above $90 \%$ in rest, and when sleeping [79]. As a general warning mechanical ventilation possess a high-risk during induction and ventilation itself with potential negative haemodynamic effect (systemic vasodilation, increasing PVR); thus auto or low $\left(\leq 10 \mathrm{cmH}_{2} \mathrm{O}\right)$ PEEP, a $6 \mathrm{~mL} / \mathrm{kg} / \mathrm{min}$ tidal volume if tolerated, a plateau pressure lower than $30 \mathrm{cmH}_{2} \mathrm{O}$ are recommended in $\mathrm{PAH}$ patients who experienced ARDS [60,90]. For patients with refractory hypoxemia, alternative support methods such as high-flow nasal oxygen cannula, continuous positive airways pressure (CPAP) and non-invasive ventilation can be used [91].

\section{Optimising fluid balance}

Fluid management is challenging in $\mathrm{PAH}$ patients with acute right heart failure. Usually PAH patients who experience an acute episode of decompensation are hypervolemic, but optimal filling point is variable [66]. Tailored dosage of loop diuretics (such as furosemide) in continuous infusion will determine volume depletion with reduction of RV preload, RV wall tension, augmentation of ventricular interdependence and LV diastolic compliance [76]. In selected patients a combination of loop diuretics and thiazides or ultrafiltration may be needed. Diuretic therapy supplementation by adding spironolactone in higher doses may be successful in acute decompensated episodes of HF in PAH patients as they are susceptible for secondary hyperaldosteronism [92,93].Management of hypervolemia by venovenous ultrafiltration is retained in particular cases of hypervolemic PAH patients [16,93].

Vasopressors, inotropes and PAH specific drugs used in ICU settings

Optimizing the cardiac output, myocardial contractility, and preserving systemic blood pressures with direct effect of coronary arteries perfusion pressure by increasing systemic vascular resistance are in close conjunction with above mentioned measures. The effects of commonly vasopressors and inotropes used in ICU admitted PAH patients are presented in table 3 (abbreviations are same as above). The use of these drugs should be well individualised.

Afterload pressure decreasing is important to enhance RV function via mechanisms targeting RV wall tension, rebalancing oxygen delivery-consumption, improving coronary perfusion, increasing RV stroke volume and LV filling [60]. All approved drugs for PAH treatment can be used (see table 2). Typically, due to rapid onset, shorter half-time, titratability, pronounced afterload reduction and reduction in mortality, continuous infusion of epoprostenol is the first option [94]. A special attention must be conferred to selexipag (a prostacyclin receptor agonist) which was not studied in acute care settings, but treatment should not be discontinued in already treated patients [95]. The rapid onset (15 minutes), peak effects (60 minutes) and a 4-6 hour duration of action of Sildenafil determine an increase of CO and decrease of MPAP and PVR; it can be used in ICUs orally and/or intravenously with caution due to side-effects $[10,96]$. Initiation of up-front triple therapy with epoprostenol, ERA's and PDE-5 is also suitable for critically ill PAH patients [97]. 
Table 3. Vasopressors and inotropes effects on hemodynamics

\begin{tabular}{|c|c|c|c|c|}
\hline Effect & $\mathrm{CO}$ & HR & SVR & PVR \\
\hline$\uparrow \uparrow$ & $\begin{array}{l}\text { Dobutamine } \\
\text { Milrinone } \\
\text { Levosimendan } \\
\text { Epinephrine }\end{array}$ & $\begin{array}{l}\text { Dopamine } \\
\text { Epinephrine }\end{array}$ & $\begin{array}{c}\text { Epinephrine } \\
\text { Norepinephrine } \\
\text { Vasopressin }\end{array}$ & - \\
\hline$\uparrow$ & $\begin{array}{c}\text { Dopamine } \\
\text { Norepinephrine }\end{array}$ & $\begin{array}{c}\text { Dobutamine } \\
\text { Norepinephrine }\end{array}$ & Dopamine & $\begin{array}{c}\text { Dopamine } \\
\text { Norepinephrine }\end{array}$ \\
\hline$\uparrow / \downarrow$ & Vasopressin & - & - & $\begin{array}{l}\text { Epinephrine } \\
\text { Vasopressin }\end{array}$ \\
\hline$\downarrow$ & - & - & $\begin{array}{l}\text { Dobutamine } \\
\text { Milrinone } \\
\text { Levosimendan }\end{array}$ & $\begin{array}{l}\text { Dobutamine } \\
\text { Milrinone } \\
\text { Levosimendan }\end{array}$ \\
\hline
\end{tabular}

The usual dosage and duration of action of agents used to optimize preload, myocardial contractility and diminishing right ventricular afterload, including pulmonary vasodilator therapy are presented in table 4 .

\section{- Other therapeutic options}

Small and moderate pericardial effusions should be managed conservatively. In cardiac tamponade, immediate pericardiocentesis or surgical drainage is confirmed by echocardiographic parameters assessed during one respiratory cycle, using pulse wave velocity (PWV) in both mitral inflow and hepatic venous flow [98].

In particular situations of non-responsive to acute therapies cases is crucial to include the right ventricular mechanical circulatory support. Mechanical support of RV failure (i.e. extracorporeal membrane oxygenation membrane ECMO veno/venous or veno/ arterial, or pumpless membrane oxygenators PA-LA, right ventricular assist device-RVAD) can be proposed as a bridge to recovery in acute decompensated naïve $\mathrm{PAH}$ patients, in treatable causes of acute decompensation of RHF, or overpassing to lung transplantation $[16,60]$. Survival of PAH patients admitted in ICU assessed with veno/venous ECMO can be predicted by the SAVE score [99].

\section{CONCLUSIONS}

Pulmonary arterial hypertension is a progressive disease with an inexorable advance to death, irrespective

Table 4. Pharmacological options in acute right heart failure PAH patients

\begin{tabular}{|c|c|c|}
\hline Drugs & Dosage & Duration of action (t1/2) \\
\hline \multicolumn{3}{|l|}{ Vasopressors } \\
\hline Noradrenaline & $0.2-1.0 \mu \mathrm{g} / \mathrm{kg} / \mathrm{min}$ & $1-2 \min$ \\
\hline Vasopressin & 20 units $/ \mathrm{ml}$ dose $1-4$ units/hour & 4- $20 \mathrm{~min}$ \\
\hline \multicolumn{3}{|c|}{ Sympathicomimetic inotropics } \\
\hline Dopamine & $2-20 \mu \mathrm{g} / \mathrm{kg} / \mathrm{min}$ & $2 \min$ \\
\hline Dobutamine & $2-20 \mu \mathrm{g} / \mathrm{kg} / \mathrm{min}$ & $2-3 \mathrm{~min}$ \\
\hline \multicolumn{3}{|l|}{ Inodilators } \\
\hline Milrinone & $0.375-0.75 \mu \mathrm{g} / \mathrm{kg} / \mathrm{min}$ & 1-2 hours \\
\hline Levosimendan & $\begin{array}{l}0.1-0.2 \mu \mathrm{g} / \mathrm{kg} / \mathrm{min} \\
\text { (Optional bolus of } 6-12 \mu \mathrm{g} / \mathrm{kg} \text { bolus in } 10 \mathrm{~min} \text {; } \\
\text { not recommended if } \mathrm{SBP}<90 \mathrm{mmHg} \text { ) }\end{array}$ & 1 hour \\
\hline \multicolumn{2}{|c|}{ Reduction of afterload } & \\
\hline Epoprostenol & $5-20 \mu \mathrm{g} / \mathrm{kg} / \mathrm{min}$ & $2-3 \min$ \\
\hline $\begin{array}{l}\text { Iloprost } \\
\text { Intravenous }\end{array}$ & $2.5-5 \mu \mathrm{g}$ 6-9 times/day & $30 \mathrm{~min}$ \\
\hline Epoprostenol & $\begin{array}{c}\text { Titrate upward in } 2 \mathrm{ng} / \mathrm{kg} / \mathrm{min} \text { increments } \\
\text { according to effect }\end{array}$ & $2-3 \min$ \\
\hline Iloprost & $1-5 \mathrm{ng} / \mathrm{kg} / \mathrm{min}$ & $30 \mathrm{~min}$ \\
\hline
\end{tabular}


of advances in diagnosis and medical approach. In time right heart failure develops as a consequence of the disease progress. Understanding the pathophysiology of the right ventricle, the ventricular interdependence and hemodynamic, advocate the monitoring and the treatment, and expert center team management should be the therapeutic approach of severe right-sided heart decline PAH patients. Intensive care support goal is focused on optimising the fluid status, cardiac output and blood pressure, reduce the right ventricle afterload, ward off the intubation, and avoiding development of multisystem organ failure.

\section{- AUTHOR CONTRIBUTION}

All authors made substantial contributions to conceptualization, acquisition, analysis and interpretation of presented information; writing and original draft preparation and revising it for important intellectual content; agreed submission to the current journal; gave final approval of the version to be published; and agree to be accountable for all aspects of the work.

\section{ACKNOWLEDGMENTS}

This paper was partially supported by the "George Emil Palade" University of Medicine, Pharmacy, Science and Technology of Targu Mures, Romania, Research Grant number 615/13/17.01.2019.

\section{CONFLICT OF INTEREST}

All authors declare that they have no conflicts of interest related to this study.

\section{REFERENCES}

1. Galiè N, Humbert M, Vachiery JL, et al; ESC Scientific Document Group. 2015 ESC/ERS Guidelines for the diagnosis and treatment of pulmonary hypertension: The Joint Task Force for the Diagnosis and Treatment of Pulmonary Hypertension of the European Society of Cardiology (ESC) and the European Respiratory Society (ERS): Endorsed by: Association for European Paediatric and Congenital Cardiology (AEPC), International Society for Heart and Lung Transplantation (ISHLT). Eur Heart J. 2016;37(1):67-119.

2. Galiè N, Channick RN, Frantz RP, et al. Risk stratification and medical therapy of pulmonary arterial hypertension. Eur Respir J. 2019;53(1):1801889.

3. Konstam MA, Kiernan MS, Bernstein D, et al C; American Heart Association Council on Clinical Cardiology; Council on Cardiovascular Disease in the Young; and Council on Cardiovascular Surgery and Anesthesia. Evaluation and management of right-sided heart failure: a scientific statement from the American Heart Association. Circulation. 2018;137(20):e578-e622.

4. Haddad F, Doyle R, Murphy DJ, Hunt SA. Right ventricular function in cardiovascular disease, part II: pathophysiology, clinical importance, and management of right ventricular failure. Circulation. 2008;117(13):1717-31.

5. Nowroozpoor A, Malekmohammad M, Seyyedi SR, Hashemian SM. Pulmonary hypertension in intensive care units: an updated review. Tanaffos. 2019;18(3):180-207.

6. Bauchmuller K, Condliffe R, Southern J, et al. Critical care outcomes in patients with pre-existing pulmonary hypertension: insights from the ASPIRE registry. ERJ Open Res. 2021;7(2):00046-2021.

7. Huynh TN, Weigt SS, Sugar CA, Shapiro S, Kleerup EC. Prognostic factors and outcomes of patients with pulmonary hypertension admitted to the intensive care unit. J Crit Care. 2012;27(6):739.e7-13.

8. Saydain G, Awan A, Manickam P, Kleinow P, Badr S. Pulmonary hypertension an independent risk factor for death in intensive care unit: correlation of hemodynamic factors with mortality. Clin Med Insights Circ Respir Pulm Med. 2015;9:27-33.

9. Sztrymf B, Souza R, Bertoletti L, et al. Prognostic factors of acute heart failure in patients with pulmonary arterial hypertension. Eur Respir J. 2010;35(6):1286-93.

10. Jentzer JC, Mathier MA. Pulmonary hypertension in the intensive care unit. J Intensive Care Med. 2016;31(6):369-85.

11. Kurzyna M, Zyłkowska J, Fijałkowska A, et al. Characteristics and prognosis of patients with decompensated right ventricular failure during the course of pulmonary hypertension. Kardiol Pol. 2008;66(10):1033-9.

12. Campo A, Mathai SC, Le Pavec J, et al. Outcomes of hospitalisation for right heart failure in pulmonary arterial hypertension. Eur Respir J. 2011;38(2):359-67.

13. Haddad F, Fuh E, Peterson T, et al. Incidence, correlates, and consequences of acute kidney injury in patients with pulmonary arterial hypertension hospitalized with acute rightside heart failure. J Cardiac Fail. 2011;17(7):533-9.

14. Torbic $\mathrm{H}$. Management of pulmonary arterial hypertension in the ICU. J Pharm Pract. 2019;32(3):303-13.

15. Olsson KM, Halank M, Egenlauf B, et al. Decompensated right heart failure, intensive care and perioperative management in patients with pulmonary hypertension: Updated recommendations from the Cologne Consensus Conference 2018. Int J Cardiol. 2018;272S:46-52.

16. Hoeper MM, Benza RL, Corris $P$, et al. Intensive care, right ventricular support and lung transplantation in patients with pulmonary hypertension. Eur Respir J. 2019;53(1):1801906.

17. Morrell NW, Aldred MA, Chung WK, et al. Genetics and genomics of pulmonary arterial hypertension. Eur Respir J. 2019;53(1):1801899. 
Available online at: www.jccm.ro

18. Hemnes AR, Beck GJ, Newman JH, et al; PVDOMICS Study Group. PVDOMICS: A multi-center study to improve understanding of pulmonary vascular disease through phenomics. Circ Res. 2017;121(10):1136-9.

19. Georgescu AM, Moldovan C, Szederjesi J, Georgescu D, Azamfirei L. Echocardiographic characteristics of pulmonary arterial hypertension in children with horizontally transmitted HIV. Adv Clin Exp Med. 2017;26(3):475-81.

20. Weatherald J, Reis A, Sitbon O, Humbert M. Pulmonary arterial hypertension registries: past, present and into the future. Eur Respir Rev. 2019;28(154):190128.

21. Swinnen K, Quarck R, Godinas L, Belge C, Delcroix M. Learning from registries in pulmonary arterial hypertension: pitfalls and recommendations. Eur Respir Rev. 2019;28(154):190050.

22. Maron BA, Galiè N. Diagnosis, treatment, and clinical management of pulmonary arterial hypertension in the contemporary era: A Review. JAMA Cardiol. 2016;1(9):105665.

23. McLaughlin VV, Archer SL, Badesch DB, et al; American College of Cardiology Foundation Task Force on Expert Consensus Documents; American Heart Association; American College of Chest Physicians; American Thoracic Society, Inc; Pulmonary Hypertension Association. ACCF/AHA 2009 expert consensus document on pulmonary hypertension a report of the American College of Cardiology Foundation Task Force on Expert Consensus Documents and the American Heart Association developed in collaboration with the American College of Chest Physicians; American Thoracic Society, Inc.; and the Pulmonary Hypertension Association. J Am Coll Cardiol. 2009;53(17):1573-619.

24. Farber HW, Miller DP, Poms AD, et al. Five-year outcomes of patients enrolled in the REVEAL Registry. Chest. 2015;148(4):1043-54.

25. Sitbon O, Sattler C, Bertoletti L, et al. Initial dual oral combination therapy in pulmonary arterial hypertension. Eur Respir J. 2016;47(6):1727-36.

26. Badesch DB, Raskob GE, Elliott CG, et al. Pulmonary arterial hypertension: baseline characteristics from the REVEAL Registry. Chest. 2010;137(2):376-87.

27. Humbert $\mathrm{M}$, Sitbon $\mathrm{O}$, Chaouat $\mathrm{A}$, et al. Pulmonary arterial hypertension in France: results from a national registry. Am J Respir Crit Care Med. 2006;173(9):1023-30.

28. Peacock AJ, Murphy NF, McMurray JJ, Caballero L, Stewart S. An epidemiological study of pulmonary arterial hypertension. Eur Respir J. 2007;30(1):104-9.

29. McGoon MD, Benza RL, Escribano-Subias P. Pulmonary arterial hypertension: epidemiology and registries. J Am Coll Cardiol. 2013;62(25 Suppl):D51-9.

30. Bergot $E$, De Leotoing $L$, Bendjenana $H$, et al. Hospital burden of pulmonary arterial hypertension in France. PLoS One. 2019;14(9):e0221211.

31. D'Alonzo GE, Barst RJ, Ayres SM, et al. Survival in patients with primary pulmonary hypertension. Results from a national
The Journal of Critical Care Medicine 2021;7(3) • 181

prospective registry. Ann Intern Med. 1991;115(5):343-9.

32. Humbert $\mathrm{M}$, Sitbon $\mathrm{O}$, Yaïci A, et al; French pulmonary arterial hypertension network. Survival in incident and prevalent cohorts of patients with pulmonary arterial hypertension. Eur Respir J. 2010;36(3):549-55.

33. Thenappan T, Shah SJ, Rich S, Tian L, Archer SL, GombergMaitland M. Survival in pulmonary arterial hypertension: a reappraisal of the $\mathrm{NIH}$ risk stratification equation. Eur Respir J. 2010;35(5):1079-87.

34. Silber D, Lachmann J. Invasive hemodynamics of pulmonary disease and the right ventricle. Interv Cardiol Clin. 2017;6(3):329-43.

35. Moscucci M (ed). Grossman \& Baim's Cardiac Catheterization, Angiography, and Intervention, Wolters Kluwer, 9 th Ed., 2021.

36. Benza RL, Gomberg-Maitland M, Elliott CG, et al. Predicting survival in patients with pulmonary arterial hypertension: The REVEAL risk score calculator 2.0 and comparison with ESC/ERSbased risk assessment strategies. Chest. 2019;156(2):323-37.

37. Benza RL, Kanwar MK, Raina A, et al. Development and validation of an abridged version of the REVEAL 2.0 risk score calculator, REVEAL Lite 2, for use in patients with pulmonary arterial hypertension. Chest. 2021;159(1):337-46.

38. Boucly A, Weatherald J, Savale L, et al. Risk assessment, prognosis and guideline implementation in pulmonary arterial hypertension. Eur Respir J. 2017;50(2):1700889.

39. Ranchoux B, Harvey LD, Ayon RJ, et al. Endothelial dysfunction in pulmonary arterial hypertension: an evolving landscape (2017 Grover Conference Series). Pulm Circ. 2018;8(1):2045893217752912

40. Yildiz M, Sahin A, Behnes M, Akin I. An expanding role of biomarkers in pulmonary arterial hypertension. Curr Pharm Biotechnol. 2017;18(6):491-4.

41. Kanwar MK. Biomarkers in pulmonary arterial hypertension: Moving closer toward precision medicine? J Heart Lung Transplant. 2020;39(4):287-8.

42. Fijalkowska A, Kurzyna M, Torbicki A, et al. Serum N-terminal brain natriuretic peptide as a prognostic parameter in patients with pulmonary hypertension. Chest. 2006;129(5):1313-21.

43. Warwick G, Thomas PS, Yates DH. Biomarkers in pulmonary hypertension. Eur Respir J. 2008;32(2):503-12.

44. Ponikowski P, Voors AA, Anker SD, et al. 2016 ESC Guidelines for the diagnosis and treatment of acute and chronic heart failure: The Task Force for the diagnosis and treatment of acute and chronic heart failure of the European Society of Cardiology (ESC). Developed with the special contribution of the Heart Failure Association (HFA) of the ESC. Eur J Heart Fail. 2016;18(8):891-975.

45. Rubio-Gracia J, Giménez-López I, Josa-Laorden C, et al. Prognostic value of multimodal assessment of congestion in acute heart failure. Rev Clin Esp (Barc). 2021;221(4):198-206.

46. Pezzuto B, Badagliacca R, Poscia R, et al. Circulating biomarkers in pulmonary arterial hypertension: update and future direction. J Heart Lung Transplant. 2015;34:282-305. 
182 The Journal of Critical Care Medicine 2021;7(3)

47. Hemnes AR. Current and emerging biomarkers for pulmonary hypertension. Adv Pulm Hypertens. 2018;16:136-40.

48. Simpson CE, Damico RL, Hassoun PM, et al. Noninvasive prognostic biomarkers for left-sided heart failure as predictors of survival in pulmonary arterial hypertension. Chest. 2020;157(6):1606-16.

49. Samokhin AO, Stephens T, Wertheim BM, et al. NEDD9 targets COL3A1 to promote endothelial fibrosis and pulmonary arterial hypertension. Sci Transl Med. 2018;10(445):eaap7294.

50. Coons JC, Pogue K, Kolodziej AR, Hirsch GA, George MP. Pulmonary arterial hypertension: a pharmacotherapeutic update. Curr Cardiol Rep. 2019;21(11):141.

51. Dodson MW, Brown LM, Elliott CG. Pulmonary arterial hypertension. Heart Fail Clin. 2018;14(3):255-69.

52. Price LC, Dimopoulos K, Marino P, et al. The CRASH report: emergency management dilemmas facing acute physicians in patients with pulmonary arterial hypertension. Thorax. 2017;72(11):1035-45.

53. Cassady SJ, Ramani GV. Right heart failure in pulmonary hypertension. Cardiol Clin. 2020;38(2):243-55.

54. Siehr SL, Ivy DD, Miller-Reed K, Ogawa M, Rosenthal DN, Feinstein JA. Children with pulmonary arterial hypertension and prostanoid therapy: long-term hemodynamics. J Heart Lung Transplant. 2013;32(5):546-52.

55. Sandoval J. Interventional therapies in pulmonary hypertension. Rev Esp Cardiol (Engl Ed). 2018;71(7):565-74.

56. Vonk Noordegraaf A, Haddad F, Chin KM, et al. Right heart adaptation to pulmonary arterial hypertension: physiology and pathobiology. J Am Coll Cardiol. 2013;62:D22-33.

57. Vonk Noordegraaf A, Chin KM, Haddad F, et al. Pathophysiology of the right ventricle and of the pulmonary circulation in pulmonary hypertension: an update. Eur Respir J. 2019;53(1):1801900.

58. Mehra MR, Park MH, Landzberg MJ, Lala A, Waxman AB; International Right Heart Failure Foundation Scientific Working Group. Right heart failure: toward a common language. J Heart Lung Transplant. 2014;33(2):123-6.

59. Harjola VP, Mebazaa A, Čelutkienè J, et al. Contemporary management of acute right ventricular failure: a statement from the Heart Failure Association and the Working Group on Pulmonary Circulation and Right Ventricular Function of the European Society of Cardiology. Eur J Heart Fail. 2016;18(3):226-41.

60. Inampudi C, Tedford RJ, Hemnes AR, et al. Treatment of right ventricular dysfunction and heart failure in pulmonary arterial hypertension. Cardiovasc Diagn Ther. 2020;10(5):1659-74.

61. Sanders JL, Koestenberger M, Rosenkranz S, Maron BA. Right ventricular dysfunction and long-term risk of death. Cardiovasc Diagn Ther. 2020;10(5):1646-58.

62. Hermens JA, Donker DW. Right ventricular failure in the ICU: a practical approach. Neth J Crit Care. 2018;26(3):111-7.

63. Rajagopalan N, Dohi K, Simon MA, et al. Right ventricular
Available online at: www.jccm.ro

dyssynchrony in heart failure: a tissue Doppler imaging study. J Card Fail. 2006;12(4):263-7.

64. Vitarelli A, Mangieri E, Terzano C, et al. Three-dimensional echocardiography and 2D-3D speckle-tracking imaging in chronic pulmonary hypertension: diagnostic accuracy in detecting hemodynamic signs of right ventricular (RV) failure. J Am Heart Assoc. 2015;4(3):e001584.

65. Marik PE. Obituary: pulmonary artery catheter 1970 to 2013. Ann Intensive Care. 2013;3(1):38.

66. de Asua I, Rosenberg A. On the right side of the heart: Medical and mechanical support of the failing right ventricle. J Intensive Care Soc. 2017;18(2):113-20.

67. Litton E, Morgan M. The PiCCO monitor: a review. Anaesth Intensive Care. 2012;40(3):393-409.

68. Pearse RM, Ikram K, Barry J. Equipment review: an appraisal of the LiDCO plus method of measuring cardiac output. Crit Care. 2004;8(3):190-5.

69. Sharma RK, Oliveira AC, Yang T, et al. Pulmonary arterial hypertension-associated changes in gut pathology and microbiota. ERJ Open Res. 2020;6(3):00253-2019.

70. Ranchoux B, Bigorgne A, Hautefort A, et al. Gut-lung connection in pulmonary arterial hypertension. Am J Respir Cell Mol Biol. 2017;56(3):402-5.

71. Bandorski D, Bogossian H, Stempfl J, et al. Prognostic relevance of nonsustained ventricular tachycardia in patients with pulmonary hypertension. Biomed Res Int. 2016;2016:1327265.

72. Cannillo M, Grosso Marra W, et al. Supraventricular arrhythmias in patients with pulmonary arterial hypertension. Am J Cardiol. 2015;116(12):1883-9.

73. Middleton JT, Maulik A, Lewis R, et al. Arrhythmic burden and outcomes in pulmonary arterial hypertension. Front Med (Lausanne). 2019;6:169.

74. Mercurio V, Peloquin G, Bourji KI, et al. Pulmonary arterial hypertension and atrial arrhythmias: incidence, risk factors, and clinical impact. Pulm Circ. 2018;8(2):2045894018769874.

75. Olsson KM, Nickel NP, Tongers J, Hoeper MM. Atrial flutter and fibrillation in patients with pulmonary hypertension. Int J Cardiol. 2013;167(5):2300-5.

76. Granton J, Mercier O, De Perrot M. Management of severe pulmonary arterial hypertension. Semin Respir Crit Care Med. 2013;34(5):700-13.

77. Cirulis MM, Ryan JJ, Archer SL. Pathophysiology, incidence, management, and consequences of cardiac arrhythmia in pulmonary arterial hypertension and chronic thromboembolic pulmonary hypertension. Pulm Circ. 2019;9(1):2045894019834890.

78. Bandorski D, Bogossian H, Ghofrani A, Schmitt J, Höltgen R. Tachykardien bei pulmonalarterieller hypertonie [Tachycardia and pulmonary arterial hypertension]. Herzschrittmacherther Elektrophysiol. 2020;31(1):33-8.

79. Grünig E, Benjamin N, Krüger $U$, et al. General measures 
Available online at: www.jccm.ro

and supportive therapy for pulmonary arterial hypertension: Updated recommendations from the Cologne Consensus Conference 2018. Int J Cardiol. 2018;272S:30-6.

80. Ponikowski P, Kirwan BA, Anker SD, et al; AFFIRM-AHF investigators. Ferric carboxymaltose for iron deficiency at discharge after acute heart failure: a multicentre, double-blind, randomised, controlled trial. Lancet. 2020;396(10266):1895904.

81. DeFilippis EM, Van Spall HGC. In acute HF and iron deficiency, IV ferric carboxymaltose reduced HF hospitalizations, but not CV death, at 1 y. Ann Intern Med. 2021;174(4):JC45.

82. Thibault N, Morrill AM, Willett KC. Idarucizumab for Reversing Dabigatran-Induced Anticoagulation: A Systematic Review. Am J Ther. 2018;25(3):e333-e338.

83. Carpenter E, Singh D, Dietrich E, Gums J. Andexanet alfa for reversal of factor Xa inhibitor-associated anticoagulation. Ther Adv Drug Saf. 2019;10:2042098619888133.

84. Moen CA, Burrell A, Dunning J. Does tranexamic acid stop haemoptysis? Interact Cardiovasc Thorac Surg. 2013;17(6):991-4.

85. Cantu J, Wang D, Safdar Z. Clinical implications of haemoptysis in patients with pulmonary arterial hypertension. Int J Clin Pract Suppl. 2012;(177):5-12.

86. Franquiz MJ, Hines MC, Yeung SYA. Comparison of Two WeightBased Desmopressin Dosing Strategies for Spontaneous Bleeding. Ann Pharmacother. 2018;52(6):527-32.

87. Konstantinides SV, Meyer G, Becattini C, et al; ESC Scientific Document Group. 2019 ESC Guidelines for the diagnosis and management of acute pulmonary embolism developed in collaboration with the European Respiratory Society (ERS). Eur Heart J. 2020;41(4):543-603.

88. Roberts $\mathrm{DH}$, Lepore JJ, Maroo A, et al. Oxygen therapy improves cardiac index and pulmonary vascular resistance in patients with pulmonary hypertension. Chest 2001;120:154755.

89. Price LC, Wort SJ, Finney SJ, Marino PS, Brett SJ. Pulmonary vascular and right ventricular dysfunction in adult critical care:
The Journal of Critical Care Medicine 2021;7(3) • 183

current and emerging options for management: a systematic literature review. Crit Care. 2010;14(5):R169.

90. Needham DM, Colantuoni E, Mendez-Tellez PA, et al. Lung protective mechanical ventilation and two year survival in patients with acute lung injury: prospective cohort study. BMJ. 2012;344:e2124.

91. Rush B, Biagioni BJ, Berger L, McDermid R. Mechanical ventilation outcomes in patients with pulmonary hypertension in the United States: A National Retrospective Cohort Analysis. J Intensive Care Med. 2017;32(10):588-92.

92. Bansal S, Lindenfeld J, Schrier RW. Sodium retention in heart failure and cirrhosis: potential role of natriuretic doses of mineralocorticoid antagonist? Circ Heart Fail. 2009;2(4):3706.

93. Felker GM, Mentz RJ. Diuretics and ultrafiltration in acute decompensated heart failure. J Am Coll Cardiol. 2012;59(24):2145-53.

94. Sitbon O, Vonk Noordegraaf A. Epoprostenol and pulmonary arterial hypertension: 20 years of clinical experience. Eur Respir Rev. 2017;26(143):160055.

95. Sitbon O, Channick R, Chin KM, et al; GRIPHON Investigators. Selexipag for the treatment of pulmonary arterial hypertension. N Engl J Med. 2015;373(26):2522-33.

96. Vachiery $J L$, Huez S, Gillies $H$, et al. Safety, tolerability and pharmacokinetics of an intravenous bolus of sildenafil in patients with pulmonary arterial hypertension. $\mathrm{Br} \mathrm{J}$ Clin Pharmacol 2011;71(2):289-92.

97. Sitbon $O$, Jais $X$, Savale L, et al. Upfront triple combination therapy in pulmonary arterial hypertension: a pilot study. Eur Respir J 2014;43:1691-7.

98. Appleton C, Gillam L, Koulogiannis K. Cardiac Tamponade. Cardiol Clin. 2017;35(4):525-37.

99. Schmidt $M$, Burrell A, Roberts $L$, et al. Predicting survival after ECMO for refractory cardiogenic shock: the survival after venoarterial-ECMO (SAVE)-score. Eur Heart J. 2015;36(33):224656. 